EESTI NSV TEADUSTE AKADEEMIA TOIMETISED. XVII KOIDE

KEEMIA * GEOLOOGIA. 1968, Nr. 3

ИЗВЕСТИЯ АКАДЕМИИ НАУК ЭСТОНСКОИ ССР. ТОМ ХVII

Химия * ГЕОЛОГИЯ. 1968, № 3

РЭЭТ мЯНННЛЬ

\title{
ENCRINURUS SCHMIDTI sp. n. (TRILOBITA) ИЗ ЛЛАНДОВЕРИ ЭСТОНИИ
}

В 1964 году старшим геологом Управления геологии Совета Министров Эстонской ССР С. Йги на р. Коновере, вблизи деревни Лятикюла (около $20 \mathrm{\kappa м} \mathrm{к} \mathrm{юго-западу} \mathrm{от} \mathrm{пос.} \mathrm{Мярьямаа),} \mathrm{было} \mathrm{открыто} \mathrm{новое}$ обнажение глинистой (западной) фации адавереского горизонта. Палеонтологический материал, собранный из этого обнажения (С. Иыги, А. Рыымусоксом, М. Рубелем), содержит весьма хорошо сохранившиеся остатки трилобитов, среди которых имеются новые виды родов Encrinurus, Eophacops и Leonaspis. В данной статье из этой фауны описывается новый представитель рода Encrinurus.

Весь материал по трилобитам из Лятикюла, в том числе типы нового вида Encrinurus, хранится в фондах Геологического музея Института геологии АН ЭССР в Таллине.

\section{Encrinurus schmidti sp. n. Табл. I, II}

Голотип. Спинной щит с гипостомой, $\operatorname{Tr} 2450$. Лландовери, адавереский горизонт $(\mathrm{H})$, р. Коновере, дер. Лятикюла, Эстония. Колл. М. Рубеля.

Ма те ри ал. 5 спинных щитов (из них 2 с гипостомами), 11 кранюдий (из них 2 с гипостомами) и 9 пигидий.

Ди агноз. Глабель умеренно выпуклая, относительно длинная. Спинные борозды глубокие, дугообразно загнутые. Глабель покрыта небольшими бугорками, количество которых у изученного материала колеблется от 59 до 76 . На предглабельном поле 8-10 бугорков, в середине поля бугорков нет. На боковой краевой кайме, в передней ее части, встречаются очень слабо развитые бугорки. Гипостома ромбическая, с остроугольными передним и задним окончаниями. Пигидий удлиненнотреугольный, со слабыми бугорками на рахисе и плевральных сегментах. Количество плевральных сегментов пигидия 7, сегментов рахиса 19. Имеется хвостовой шип.

О пи сание. Глабель умеренно выпуклая, удлиненная. Спинные борозды относительно узкие и глубокие, дугообразно расходящиеся. Передняя часть глабели примерно в два раза шире задней; максимальная ширина немного меньше длины глабели.

Глабельные лопасти выражены слабо. Базальные лопасти развиты в виде небольших валиков, между которыми располагаются два бугорка. Передние лопасти имеют вид крупных бугорков. Вместо борозд глабели имеются небольшие депрессии между бугорками. Предглабельная борозда выражена в виде слабой вдавленности только по бокам.

6 ENSV TA Toimetised K*G-3 68 
Глабель покрыта небольшими бугорками, количество которых у изученного материала колеблется от 59 до 76. Число бугорков изменяется независимо от размеров глабели, т. е. от возраста изученных

Таблица 1

\begin{tabular}{c|c|c|c|c}
\hline $\begin{array}{c}\text { Номер } \\
\text { экземпляра }\end{array}$ & $\begin{array}{c}\text { Длина глабели, } \\
\text { м.м }\end{array}$ & $\begin{array}{c}\text { Ширина гла- } \\
\text { бели впереди, } \\
\text { м.м }\end{array}$ & $\begin{array}{c}\text { Количество } \\
\text { бугорков } \\
\text { глабели }\end{array}$ & $\begin{array}{c}\text { Количество } \\
\text { бугорков на } \\
\text { предллабельном } \\
\text { поле }\end{array}$ \\
\hline & & & & \\
$\operatorname{Tr} 2455$ & 9,5 & $\sim 9$ & 65 & 8 \\
$\operatorname{Tr} 2444$ & 8,0 & $-7,5$ & $60-62$ & 10 \\
$\operatorname{Tr} 2442$ & 7,8 & 7,3 & 68 & 8 \\
$\operatorname{Tr} 2453$ & 7,8 & 7,5 & 57 & 10 \\
$\operatorname{Tr} 2450$ & 7,6 & 6,4 & 58 & 9 \\
$\operatorname{Tr} 2443$ & 7,4 & 6,5 & 64 & 8 \\
$\operatorname{Tr} 2456$ & 7,2 & 6,0 & $76-77$ & 9 \\
$\operatorname{Tr} 2448$ & 6,6 & 6,0 & 63 & 10 \\
$\operatorname{Tr} 2493$ & 6,0 & 5,5 & 59 & \\
$\operatorname{Tr} 2446$ & 5,5 & 5,5 & 70 & \\
\end{tabular}

экземпляров (см. табл. 1). На предглабельном поле имеется от 8 до 10 бугорков (также независимо от возраста особей). В середине поля бугорков нет, но отмечается слабая вдавленность. При наличии 9 бугорков во всех четырех рассмотренных случаях один небольшой бугорок находится в середине правой части поля, где у экземпляров с 8 бугорками расстояние между бугорками сравнительно большое.

Бугорки имеют разные размеры. Самые крупные из них (диам. около 1 мм) находятся по бокам глабели. На предглабельном поле диаметр бугорков около 0,7 мм, на остальной части глабели обычно не превышает 0,5 мм.

На верхушке бугорков глабели обычно находится одна пора; число пор увеличивается на бугорках предглабельного поля или остальной части головного щита.

Поверхность бугорков зернистая. Зернистость практически отсутствует или очень мелкая в пространстве между бугорками глабели; на предглабельном поле она выражена слабо, а на передних и боковых краевых каймах относителььно грубая.

Расположение бугорков в задней части глабели по системе Р. Триппа (Tripp, 1962) следующее: I -1 ; II $-3,2 *$, 1 ; iii -0 ; III -3 , $2_{*}^{*}, 1$. Такое симметричное расположение бугорков наблюдается у шести нз десяти изученных глабелей. У четырех остальных экземпляров отмечается небольшое отклонение от описанной выше схемы, выражающееся в наличии обычно небольших, несимметрических бугорков или в отсутствии некоторых второстепенных бугорков.

В передней части глабели бугорки расположены менее правильно.

Затылочное кольцо в поперечном сечении выпуклое и значительно шире базальной части глабели. Затылочная борозда довольно глубокая, загнута вперед.

Щеки умеренно выпуклые; свободные щеки протягиваются почти вертикально вниз и назад. Щечные шипы почти у всех изученных экземпляров частично отломаны; у большинства из них они были развиты, по-видимому, лишь в виде небольшого заострения (табл. II, фиг. 3) и только в редких случаях протягивались в длину примерно на 2 мм (табл. II, фиг. 5).

Передниє ветви лицевых швов, отделяющие предглабельное поле от 
псевдоглабельного, приближаются друг к другу под тупым углом (около $\left.130-140^{\circ}\right)$. Задние ветви пересекают диагонально щечное поле и после перехода на боковую краевую кайму круто поворачиваются назад.

Расположенные близко к глабели глаза имеют коническую форму, y основания сужены. Основание их гладкое, без бугорков.

Псевдоглабельное поле и щеки покрыты бугорками, исчезающими около щечного угла и на каймах. Лишь на передней кайме и в передней части боковой каймы имеются отдельные очень низкие бугорки. Глаза окружены бугорками в виде венка, нередко радиально-эллиптическими. Венок бугорков несколько отдален от основания глаза, кроме внутренней стороны, где они располагаются у самого основания. Снаружи венка на свободных щеках встречаются единичные небольшие бугорки и маленькие углубления, иногда имеющие эллиптическую форму.

Дублюра впереди узкая, сильно расширяется до аподемы и дальше снова суживается. Рострум имеет вид длинного прямоугольника.

Гипостома ромбическая, с заостренными задним и передним окончаниями. Центральное тело ее овальное, сильно выпуклое в поперечном и умеренно выпуклое в продольном сечении; образует $4 / 5$ всей длины гипостомы. Макулы расположены под углом около $45^{\circ} \mathrm{K}$ оси гипостомы. Кайма гипостомы узкая, расширяется заметно у крыльев и заднего конца ее, образуя заостренный язык. Основная часть центрального тела покрыта довольно сильно выраженной зернистостью, несколько более слабой на языке и каймах. Задняя подножная часть тела и окрестность макулы гладкие.

Туловище умеренно выпуклое, состоит из 11 сегментов. Ширина рахиса несколько меньше $1 / 3$ ширины всего туловища. Сегменты рахиса в средней своей части изогнуты вперед. Сочленовные полукольца, а также борозды между ними и сегментами четкие. Спинные борозды по глубине и ширине умеренные. Плевры прямые, горизонтальные в проксимальной своей части, в дистальной части повернуты назад и вниз. В центральной части пятого, седьмого и десятого сегментов рахиса находятся очень низкие, едва заметные бугорки с несколькими порами.

Пигидий треугольного очертания, его длина больше ширины. Спинные борозды слабо дугообразные; относительно низкие и узкие в передней части пигидия, они постепенно уменьшаются в задней части и совершенно исчезают. Количество сегментов рахиса обычно 19 (из восьми изученных пигидий лишь y одного имеется 20 сегментов). Первый сегмент отделен от второго бороздой, развитой более или менее одинаково по всему своему

Схема расположения бугорков на рахисе хвостового щита у различных экземпляров E. schmidti. Отсутствующие или плохо сохранившиеся сегменты заштрихсваны.

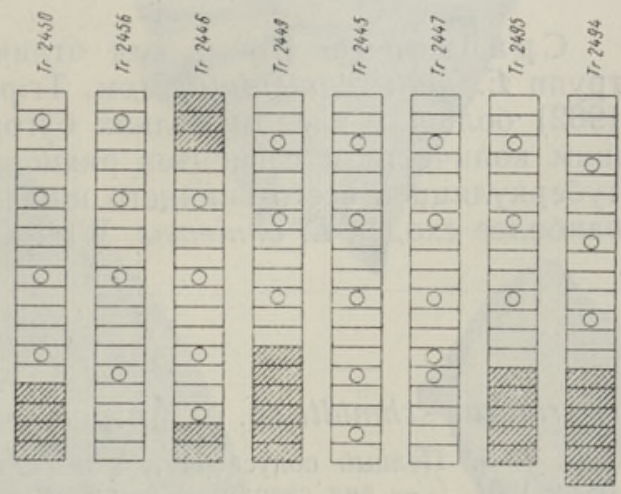

протяжению. Следующие борозды в средней части рахиса намечаются лишь в виде слабых депрессий, а у последних девяти сегментов осевая часть рахиса совсем гладкая. 
Бугорки в $2 / 3$ передней части рахиса располагаются обычно, начиная от второго или третьего сегмента, через каждые три сегмента. В задней части рахиса они расположены более густо и менее регулярно (см. рисунок). У экземпляра с 20 сегментами, бугорки, в отличие от других экземпляров, находятся ближе к концу пигидия (рисунок, $\operatorname{Tr} 2494)$. На бугорках рахиса обычно две поры.

Плевральных сегментов семь. Поверхность их слегка уплощена. Сегменты слабо расширяются к наружной стороне и более резко - в самых концах. Интерплевральные борозды широкие и суживаются только в самых проксимальных и дистальных концах. На плеврах находятся очень низкие бугорки с одной или несколькими порами, расположенные обычно в проксимальной, реже в средней части плевры. Хвостовой шип находится между седьмой парой плевры и может составлять около 1/4 всей длины пигидия (табл. II, фиг. 5).

Дублюра пигидия по ширине одинаковая, поверхность ее зернистая. По краям концов плевр туловища и пигидия наблюдается горизонтальный ряд мелких пор.

Размеры (в мм) приведены в табл. 2.

Таблица 2

\begin{tabular}{l|l|l|l|l|l|l|l|l|l|}
\hline & $\operatorname{Tr} 2450$ & $\operatorname{Tr} 2456$ & $\operatorname{Tr} 2453$ & $\operatorname{Tr} 2442$ & $\operatorname{Tr} 2443$ & $\operatorname{Tr} 2455$ & $\operatorname{Tr} 2446 \mathrm{~b}$ \\
\hline
\end{tabular}

Длина спинного щита

Длина головного щита

Ширина головного щита

Длина глабели

Ширина глабели впереди

Ширина глабели у основания

Длина гипостомы

Длина туловища

Ширина туловища

Ширина рахиса

Длина хвостового шцита

Ширина хвостового щита

Длина рахиса

Ширина рахиса впереди

\begin{tabular}{|c|c|c|c|c|c|}
\hline $\begin{array}{r}45,0 \\
9,8 \\
16,0 \\
7,6 \\
6,4\end{array}$ & $\begin{array}{r}40,0 \\
9,0 \\
15,0 \\
7,2 \\
6,0\end{array}$ & $\begin{array}{r}\overline{10,0} \\
20,5 \\
7,8 \\
7,5\end{array}$ & $\begin{array}{r}- \\
9,8 \\
\sim 18,0 \\
7,8 \\
7,3\end{array}$ & $\begin{array}{c}\overline{9}, 0 \\
\overline{7}, 4 \\
6,5\end{array}$ & $\begin{array}{r}\overline{-} \\
\overline{-} \\
9,5 \\
\sim 9,0\end{array}$ \\
\hline $\begin{array}{r}3,0 \\
9,5 \\
20,5 \\
15,6 \\
4,4\end{array}$ & $\begin{array}{r}3,0 \\
17,3 \\
15,0 \\
4,7\end{array}$ & $\begin{array}{r}4,5 \\
21,0 \\
19,5 \\
6,0\end{array}$ & $\begin{array}{r}4,1 \\
9,2 \\
20,0 \\
17,3 \\
5,0\end{array}$ & $\begin{array}{r}3,5 \\
8,7 \\
16,0 \\
- \\
4,9\end{array}$ & $\begin{array}{l}5,5 \\
-\end{array}$ \\
\hline 115 & 100 & - & - & - & - \\
\hline$\frac{1}{3,7}$ & $\begin{array}{l}7,3 \\
3,5\end{array}$ & - & 二 & & - \\
\hline
\end{tabular}

С равнени е. Новый вид отличается от хорошо известных видов групп E. multisegmentatus (см. Tripp, 1957) и E. punctatus (см. Tripp, $1962)$ большим числом мелких бугорков глабели, относительно небольшим количеством сегментов рахиса и плевр пигидия, а также слабой туберкуляцией всего спинного щита. Из видов этих групп с E. schmidti наиболее сходен E. onniensis, Whittard, 1938, у которого почти такое же

\section{ТАБЛИЦА I}

Encrinurus schmidti sp. n., p. Коновере, дер. Лятикюла, Н.

Фиг, 1-5. Полный полусвернутый экземпляр ( $\operatorname{Tr} 2450$, голотип), Х 3 , колл. М. Рубеля, 1964. 1 - вид сверху; 2 - вид спереди; 3 - вид сбоку; 4 - вид снизу; 5 вид туловища и пигидия сверху.

Фиг. 6. Свернутый спинной щит без пигидия $(\operatorname{Tr} 2453), \chi^{\prime} 4$, колл. А. Рыымусокса. Вид сверху.

Фиг. 7-8. Гипостома $(\operatorname{Tr} 2454), \times 4$, колл. А. Рыымусокса. $7-$ вид сверху; 8 вид сбоку. 
ТАБЛИЦА I
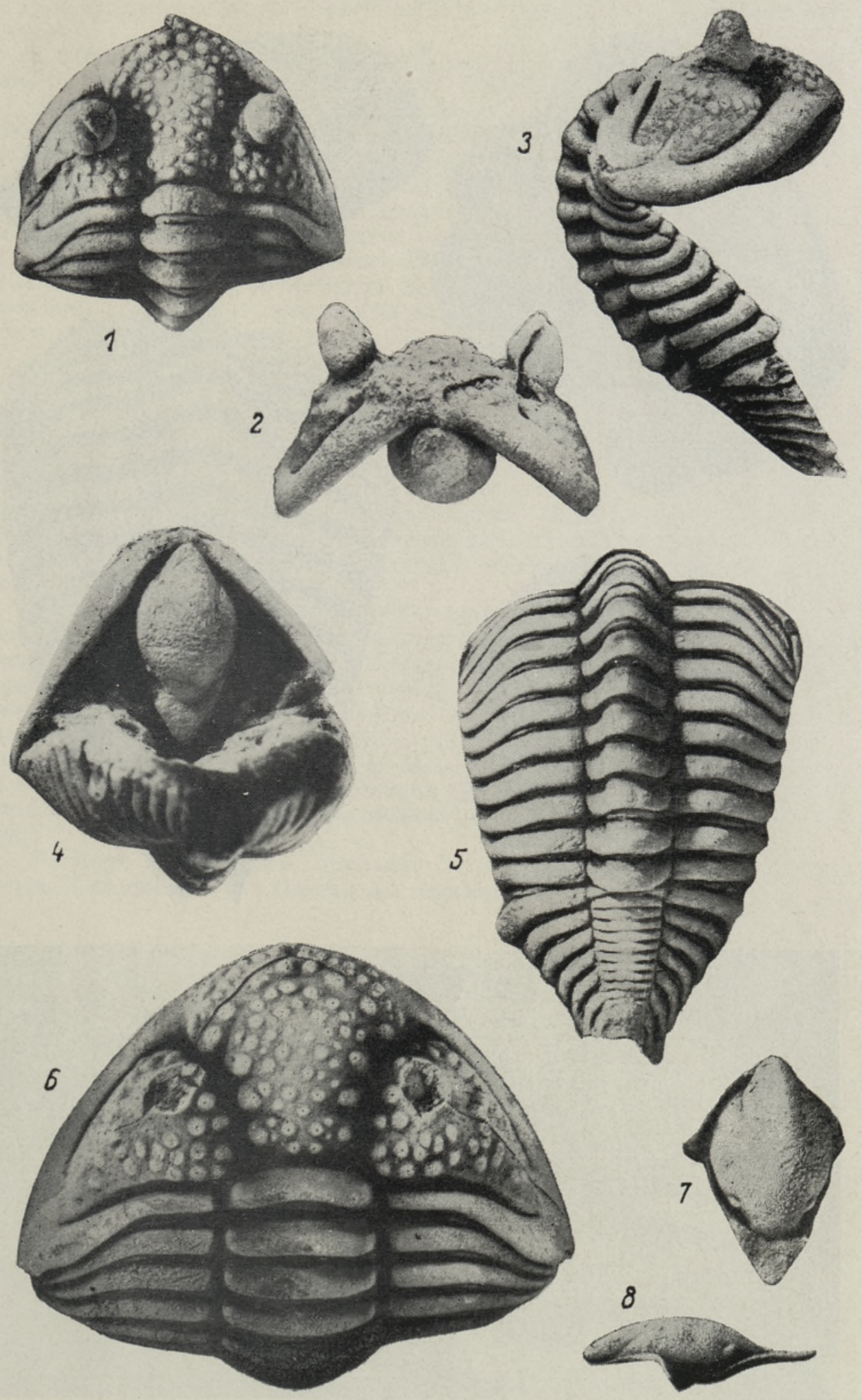
ТАБЛИЦА ІІ

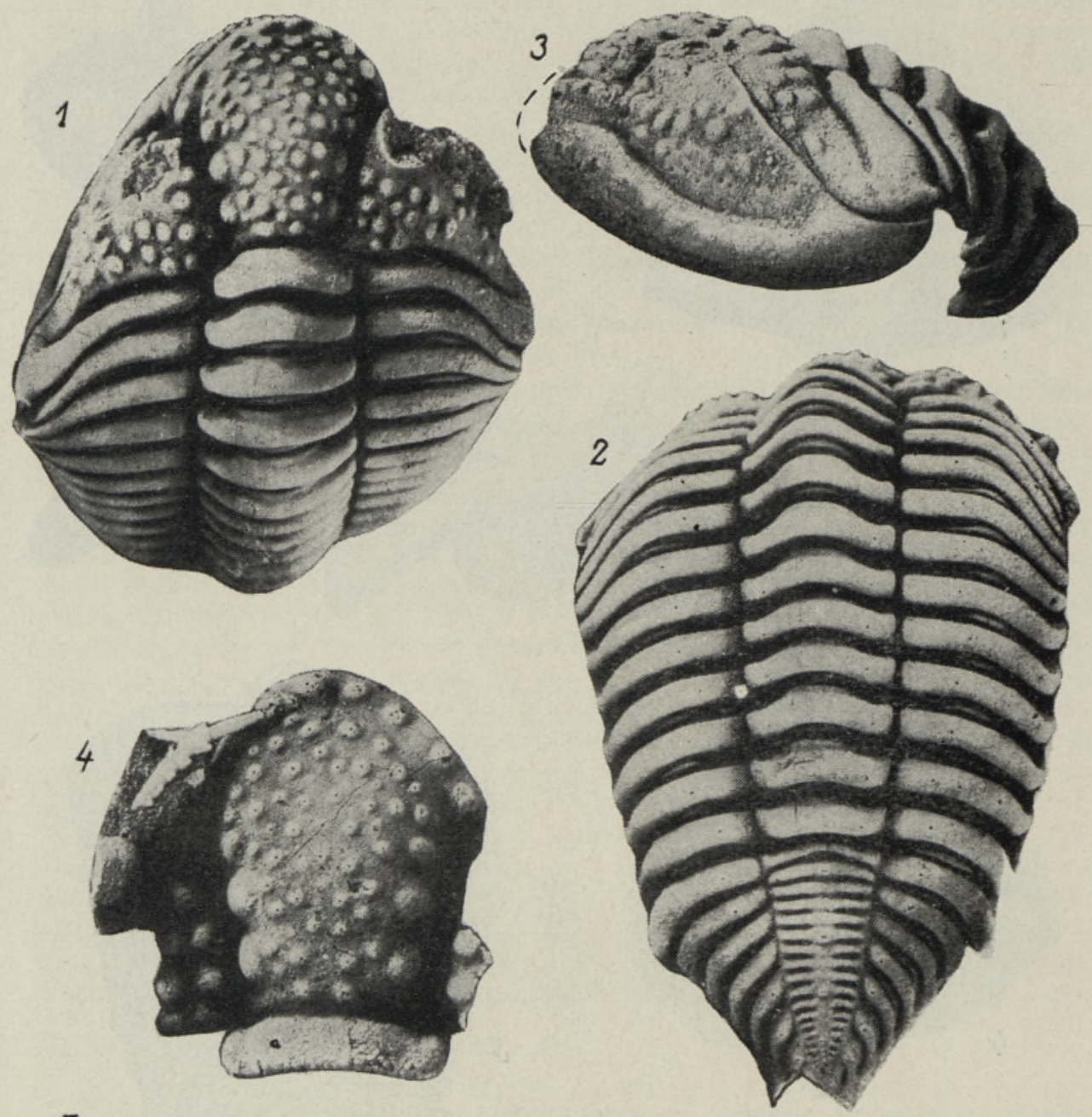

5

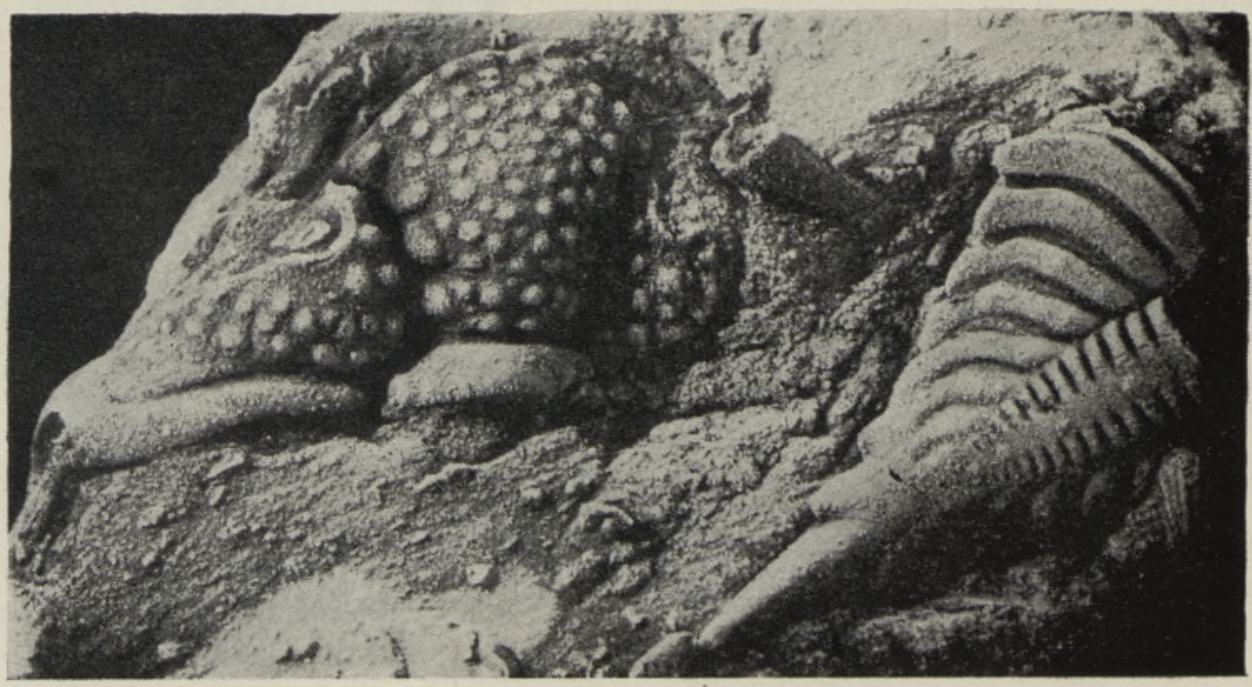


число колец на рахисе пигидия (22) и аналогичное расположение бугорков на нем. E. onniensis отличается от нашего вида расположением глаз и бугорков глабели, строением гипостомы, а также другими признаками.

E. schmidti, по-видимому, следует рассматривать как представителя особой группы видов рода Encrinurus (группа E. schmidti), к которой из силурийских видов Эстонии относятся по меньшей мере еще E. kiltsiensis Rosenstein, 1941 (райккюлаский горизонт) и E. rumbaensis Rosenstein, 1941 (адавереский горизонт).

C указанными видами E. schmidti сходен не только по общему характеру туберкуляции спинного щита и строению головного щита, но и по количеству сегментов рахиса и плевр пигидия.

От E. kiltsiensis (см. Мянниль, 1958) новый вид отличается сравнительно длинной и узкой глабелью, дугообразными спинными бороздами, большим количеством меньших по размерам бугорков глабели и наличием на них лишь одной поры. Глаза у E. schmidti, по сравнению с E. kiltsiensis, расположены ближе к спинным бороздам. Бугорки на предглабельном поле больше бугорков глабели (у E. kiltsiensis задние бугорки глабели больше предглабельных бугорков).

Пигидий нового вида отличается от пигидия E. kiltsiensis более удлиненным очертанием и наличием хвостового шипа. Количество сегментов рахиса, расположение осевых бугорков и количество плевр у сравниваемых видов более или менее одинаковое. Поры на боках нерасчлененной, гладкой части рахиса, образующие у E. kiltsiensis продольный ряд, встречаются на сегментах рахиса E. schmidti реже и расположены без особого порядка.

E. rumbaensis (см. Мянниль, 1958) отличается от E. schmidti небольшими бугорками на глабели, присутствием бугорков на боковой кайме головного щита, большим расстоянием глаз от спинных борозд и довольно резким перегибом заднего края головного щита в районе глаза. Пигидий $E$. rumbaensis отличается несколько бо́льшим количеством плевр (8) и сегментов рахиса (22), отсутствием хвостового шипа и наличием продольных рядов пор на боках нерасчлененной части рахиса. В общем хвостовой щит E. rumbaensis по сравнению с E. schmidti относительно широкий, имеет более сильную туберкуляцию и бо́льшее число пор.

Р а с п ростр анени е. Западная Эстония, р. Коновере, дер. Лятикюла. Нижний силур, адавереский горизонт (Н).

\section{ТАБЛИЦА ІІ}

Encrinurus schmidti sp. n., p. Коновере, дер. Лятикюла, Н.

Фиг. 1 -2. Неполный полусвернутый экземпляр ( $\operatorname{Tr} 2456), ~ Х 4$, колл. А. Рыымусокса. 1 - вид передней части щита сверху; 2 - вид туловища и пигидия сверху.

Фиг. 3. Неполный головной щит с сегментами туловища $(\operatorname{Tr} 2447), X 4$, колл. М. Рубеля. Вид сбоку,

Фиг. 4. Глабель ( $\operatorname{Tr} 2455), \times 4$, колл. А. Рыымусокса, вид сверху. Наверху виден перевернутый хвостовой шип того же вида.

Фиг. 5. Неполный кранидий и хвостовой щит $(\operatorname{Tr} 2446 \mathrm{a}, \mathrm{b}), \times 5$, колл. М. Рубеля. Вид сверху. 


\section{ЛН ТЕ Р А Т У $\mathrm{PA}$}

М янниль Р. М. 1958. Трилобиты семейств Cheiruridae и Encrinuridae из Эстонин. Тр. Ин-та геол. АН ЭССР, III.

Rosenstein E. 1941. Die Encrinurus-Arten des estländischen Silurs. Publ. Geol. Inst. Univ. Tartu., Nr. 62; Ann. Soc. Reb. Nat. Invest. in Univ. Tartuensis const., 47.

Tripp R. P. 1957. The trilobite Encrinurus multisegmentatus (Portlock) and allied Middle und Upper Ordovician species. Paleont., 1, p. 1.

Tripp R. P. 1962. The Silurian trilobite Encrinurus punctatus (Wahlenberg) and allied species. Paleont., 5, p. 1.

Whittard W. F. 1938. The Upper Valentian trilobite fauna of Shropshire. Annals and Mag. Natur. History, ser. II, 1, London.

\section{Институт геологи'}

Академии наук Эстонской ССР
Поступила в редакшию 15/XII 1967

\section{REET MANNIL}

\section{ENCRINURUS SCHMIDTI sp. n. (TRILOBITA) EESTI LANNDOUVERIST}

Geoloogilisel kaardistamisel 1964. aastal koguti Lääne-Eestis S. Jōgi poolt avastatud uuest adavere lademe paljandist rohkesti hea säilivusega trilobiite. Käesolevas artiklis kirjeldatakse sealt uus liik - Encrinurus schmidti (tabelid I, II) -, mis Eesti siluri liikide $E$. kiltsiensis'e ja $E$. rumbaensis'ega üldiselt sarnase tuberkulatsiooni ja pea- ning sabakilbi ehituse tôttu moodustab omaette rühma ( $E$. schmidti rühm).

\section{REET MĀNNIL}

\section{ENCRINURUS SCHMIDTI sp. n. (TRILOBITA) FROM THE LLANDOVERIAN OF ESTONIA}

Great number of well-preserved trilobites were collected in the new outcrops of Adavere Stage discovered by S. Jõgi in the course of geological mapping of WestEstonia in 1964. The present article deals with a new species from this collection, Encrinurus schmidti (Tables I, II) which, together with the Silurian species of Estonia E. kiltsiensis and E. rumbaensis, forms a separate group (the group of E. schmidti) on account of a similar tuberculation and a structure of cephalon and pygidium in common.

\section{Encrinurus schmidti sp. n. \\ Tabies I, II}

Glabella rather long and narrow. Axial furrows narrow, deep, inwards-curved. Tubercles of glabella comparatively small, 59-76 in number, in the specimens examined. Number of tubercles in the preglabellar field $-8-10$, the centre of the field without tubercles. Lateral board of the cephalon generally smooth, with a slight tuberculation in the front part only. Hypostoma oblong, rhomb-shaped, with fore and back borders forming acute angles. Pygidium oblong, triangle-shaped, with weak tuberculation on axis and pleura. Number of axial rings - 19, pleural segments - 7. Mucro occurring.

D istribution. West Estonia, River Konovere, Lätiküla, Upper Llandoverian, Adavere Stage $(\mathrm{H})$. 